\title{
A New Plasma-Surface Interactions Research Facility: PISCES-B and First Materials Erosion Experiments on Boronized Graphite*
}

\author{
Y. Hirooka, R.W. Conn, T. Sketchley, W.K. Leung \\ R. Doerner, J. Elverum, G. Gunner, M. Khandagle \\ R. Lehmer, P. Luong, Y. Ra, L. Schmitz and G. Tynan
}

UCLA-PPG-\#1253 August, 1989

\section{DISCLAIMER}

\begin{abstract}
This report was prepared as an account of work sponsored by an agency of the United Statcs Goversment. Neither the United States Government nor any agency thereof, nor any of their employees, makes any warranty, express or implied, or assumes any legal liability or eesponsibility for the aceuracy. completeness, or usefulness of any information. apparutus, product. or process disclosed, or represents that its use would not infringe privately owned rights. Reference herein to any specilic commercial product, process, or service by trade name, trademark, manufacturer, or otherwise does not necessarily constitute or imply ils endorsement, recom. mendation, or favoring by the United States Government or any agency thereof. The yiews and opinions of suthors expressed herein do not necessarily stale or renect those of the United Skates Gowernment or any agency thereof.
\end{abstract}

\author{
Institute of Plasma and Fusion Research \\ University of California, Los Angeles \\ Los Angeles, CA 90024
}




\title{
A New Plasma-Surface Interactions Research Facility: PISCES-B and First Materials Erosion Experiments on Roronized Graphite
}

\author{
Y.Hirooka, R.W.Conn, T.Sketchley, W.K.Leung, \\ R.Doemer, J.Elverum, G.Gunner, M.Khandagle, \\ R.Lehmer, P.Luong, Y.Ra, L.Schmitz and G.Tynan \\ Institute of Plasma and Fusion Research, \\ University of California, Los Angeles, California 90024
}

\begin{abstract}
A new plasma-surface interactions research facility: PISCES-B has been designed and constructed at University of Califomia, Los Angeles (UCLA). The entire vacuum chamber is bakable and a base pressure of the order of $10^{-8}$ Torr is attainable using two turbo molecular pumps with a sotal pumping speed of $6000 \mathrm{~V} / \mathrm{s}$. The PISCES-B facility can generate continuous plasmas of argon, helium, hydrogen, deuterium and nitrogen. The density of these plasmas ranges from $1 \times 10^{-11}$ to $3 \times 10^{-13} \mathrm{~cm}^{-3}$ and the electron temperature ranges from 3 to $5 \mathrm{I} \mathrm{eV}$. The plasma bombardment flux to a target surface inserted in the plasma column can be varied from $1 \times 10^{17}$ to $8 \times 10^{18}$ ions $\mathrm{cm}^{-2} \mathrm{~s}^{-1}$. Due to the high pumping speed, the neutral pressure of the working gas during plasma generation is controllable in the wide range from $3 \times 10^{-5}$ to $1 \times 10^{-3}$ Torr. These conditions are similar to those seen at the limiter and divertor areas in toroidal fusion devices. Using the PISCES-B facility, first materials erosion experiments have been conducted on 3\% boronized graphites (Toyo Tanso: G-032) and iso-graphites (POCO: AXF-SQ and Toyo Tanso: G-035) as the reference materials. The chemical sputtering yield due to hydrogen plasma bombardment at $300 \mathrm{eV}$ for $3 \%$ boronized graphite has been found to be about $30 \%$ smaller than that for iso-graphites at temperatures from room temperature to $900^{\circ} \mathrm{C}$. Also, radiation enhanced sublimation due to hydrogen plasma bombardment at $400 \mathrm{eV}$ is found to be suppressed by $20-30 \%$ for $3 \%$ boronized graphite at temperatures up to $1300^{\circ} \mathrm{C}$. No significant surface composition change is observed after hydrogen plasma bombardment to a fluence of the order of $10^{22}$ ions $\mathrm{crn}^{-2}$.
\end{abstract}




\section{INTRODUCTION}

It is well known that the plasma confinement performance in magnetic fusion devices is strongly affected by impurities due to plasma interactions with surface components. To understand the mechanisms of impurity generation associated plasmasurface interactions, considerable effort has been made in the magnetic fusion community over the last two decades. The fusion-related data base, for example, on sputtering is largely contributed by experimental work done by ion beam facilities [1]. Generally, the ion bombarding flux for these bean facilities ranges from $10^{13}$ to $10^{15}$ ions $\mathrm{cm}^{-2} \mathrm{~s}^{-1}$ because of the space charge limiration. The impurity production at the first wall is well simulated at these ion bombarding fluxes whereas this does not seem to be the case for plasma-interactive surface components such as limiters. Obviously, one should use higher ion bombarding fluxes for better simulations.

On the other hand, several measurements have been attempted to estimate plasmainduced erosion using long term coupon samples or erosion probes installed in tokamaks $[2,3]$. For most operating tokamaks, plasma confinement experiments are operated in the pulse mode, the duration of which typically ranges from $100 \mathrm{~ms}$ to $30 \mathrm{~s}$. Also, one has to consider complex materials transport and redeposition effects on these coupon erosion experiments. These arguments clearly indicate that it is difficult to conduct comprehensive plasma-surface interactions experiments in tokamaks.

Under these circumstances, a steady-state plasma facility: PISCES-A [4] was built in 1984 to conduct plasma-surface interactions experiments at high ion bombarding fluxes ranging $10^{17}-10^{18}$ ions $\mathrm{s}^{-1} \mathrm{~cm}^{-2}$ which are believed to full in the gap berween the ion bearn and in-tokamak experiments. Using this facility, one can conduct materials erosion experiments in which the degree of redeposition is controllable between a few $\%$ and about $85 \%$ [5]. To the best of our knowledge, PISCES-A still is the only non-tokamak facility that has experimentally demonstrated materials redeposition effects on the net erosion yield. Considerable amount of plasma-surface interactions data has been genesared using this facility [0]. In some cases, however, the experimental difficulty was pointed out for PISCES-A. For example, it is unavoidable to expose the material sarnple to the ait before surface analysis. This can raise uncertainty of the surface analysis data because in general plasma-bombarded surfaces are extremely air-sensitive. Also, the PISCES-A vacuum system is not bakable so that the base pressure is of the order of $10^{-6}$ Tort for most cases. For better-defined experiments, one needs lower vacuum pressures.

To improve on these experimental difficulties, a new plasma-surface interactions research facility: PISCES-B has been designed and constructed at UCLA. In this paper, 
the details of PISCES-B facility is described. Using the PISCES-B facility, first materials erosion experiments have been conducted and the data on boronized graphite materials is presented here.

\section{THE PISCES-B FACILITY}

\section{A. Major features}

A schematic diagram of the PISCES-B facility is shown in Fig. 1. The facility consists of the following components: (1) steady-state plasma generator, (2) multi-port plasma experimental chamber, (3) differentally pumped residual gas analyzer. (4) swing \& linear sample manipulator; and (5) in siru surface analysis station. The vacuum chamber sections are all bakable and the base pressure of the order of $10^{-8}$ Torr is attainable by means of two turbo molecular pumps with a total pumping speed of $6000 \mathrm{~V} / \mathrm{s}$. Major features of PISCES-B are summarized and compared with those of PISCES-A in Table 1.

For the plasma generator, $\mathrm{LaB}_{6}$ is used as the cathode material heated radiatively by a hot zungsten filament, similariy to PISCES-A [4,7]. A water-cooled copper anode is installed in an UHV compatible stainless steel chamber section and is grounded to the nıain vacuum system. The total plasma discharge power can be varied between $2 \mathrm{~kW}$ and 50 kW. The plasma generator part is pumped by a turbo molecular pump with an effective pumping speed of $1000 \mathrm{l} / \mathrm{s}$.

The main experimental chamber has 10 line-of-site ports, all the axes of which point the sample position. These line-of-site ports are installed with optical equipment such as CID camera and infra-red pyrometer for surface temperature measurements. Also, there are four cross-facing vacuum ports, made for plasma diagnostics such as Langrmir probe and micro-wave interferemeter. Two $7.5 \mathrm{~cm} \times 25 \mathrm{~cm}$ (along with the major machine axis) windows are specially designed for plasma spectroscopy measurements. A $0.5 \mathrm{~m}$ monochromator and an optical multi-channel analyzer (OMA) are arranged to obtain spectroscopic data, for example, impurity radiation profiles along with the major machine axis through these rectangular windows. All these optical viewports are equipped with fast-acting pneumatic shutters which protect the windows from being deposited with sputtered materials. The main chamber is pumped by a turbo molecular pump with a pumping of $5000 \mathrm{l} / \mathrm{s}$. The neutral gas pressures are analyzed by a residual gas analyzer (RGA). The RGA chamber is differentially pumped a $50 \mathrm{l} / \mathrm{s}$ turbo molecular pump and is separated from the main chamber with a $1 \mathrm{~mm}$ diameter orifice. 
The sample can be transpored in-between the main plasma experimental chamber and the in situ surface analysis station using the swing-linear sample manipulator. The sample manipulator travels about $90 \mathrm{~cm}$ and swings 90 degrees. In the in siru surface analysis chamber. Auger eleciron spectroscopy (AES) and secondary ion mass specuoscopy (SRM) can be performed. The ultimate pressure attainable in the AES-SIMS system is of the order of 10-10 Torr with a $170 \mathrm{l} / \mathrm{s}$ turbo molecular pump, $400 / \mathrm{s}$ ionsputter pump and a titanium sublimation well. The practical pressure during analysis, however, is of the order of $10^{-7}-10^{-8}$ Tar, controlled by the outgassing rate of the target. Typically, the sample is a circular disk with a diameter of $5 \mathrm{~cm}$ and a thickness of $5 \mathrm{~mm}$. However, it is possible to load the main chamber with a sample as large as $30 \mathrm{~cm} \times 30 \mathrm{~cm}$. This maximum loadable size for PISCES-B is even lager than the graphite component used in a major tokamak, for example DII-D [8].

\section{B. Plasma-experimental performance}

The plasma generator in PISCES-B uses the reflex-arc discharge technique and can sustain steady-state plasmas of hydrogen isotopes, helium, argon and nitrogen. By nature, the reflex arc discharge requires a floating plasma dump as the electron reflector. In PISCES-B, the material sample itself acts as the floating dump. Having a water-cooled copper dump at the regular sample position, the plasma operational space has been explored and the result is shown in Fig. 2 (a). Here, the plasma density and electron temperature were measured with a water-cooled Langmuir probe and one example is shown in Fig. (b). Notice that PISCES-B is much more flexible in generating a wider range of plasma density and electron temperature than PISCES-A. One of the crucial reasons for this is that due to the high pumping speed of the turbo molecular pump, the neutral pressure in the main chamber during steady-state plasma operation can be as low as $3 \times 10^{-5}$ Torr which is typical of the limiter region in a tokamak. Conversely, if the gate valve to the turbo pump is closed, the neutral pressure is accumulated up to $1 \times 10^{-3}$ Torr which one might call the divertor condition of a tokamak like ITER.

In PISCES- $A$, the electron energy distribution function has been found to have two componerts [9]: (1) collisionally thermalized Maxwellian distribution, the peak of which ranges from 3 to $30 \mathrm{eV}$ as measured with the Langmuir probe; and (2) not enough thermalized but accelerated to the discharge voltage as high as $=150 \mathrm{eV}$, the potential between the cathode and anode. Usually, the composition of the second component is about $10-20 \%$ of the total plasma densiry. Due to these "hot" electrons, however, it is 
difficult to analyze materials ionization and/or excitation processes in some cases. To improve this point, the length of the discharge anode length is extended to about $40 \mathrm{~cm}$ (as opposed to $20 \mathrm{~cm}$ for PISCES-A). This modification has significantly reduced the hot electron component effect in PISCES-B even at low neutral pressures. One example of Langmuir probe data to prove this point is shown in Fig. 2 (b). This data was taken at a hydrogen neutral pressure of $7 \times 10^{-5}$ Torr. Also, a hypothetical hot electron effect is illustrated in the same figure. Clearly, there is no observable hot elecuron component. In this case, the electron temperature is decluced to be $50.4 \mathrm{eV}$ and the plasma density is 4.78 $\times 10^{12} \mathrm{~cm}^{-3}$.

Similarly to PISCES-A, the intrinstic energy of ions generated in the PISCES-B plasma generator is around $1 \mathrm{eV}$ or less. Therefore, the ion bombarding energy is controlled by applying a negative dc bias to the sample, which is at the floating potential. The de bias ranges typically from 100 to $300 \mathrm{~V}$ but can be as high as $500 \mathrm{~V}$. The ions are then accelerated within the sheath region structured with the natural potential drop of $-3 k T_{e}$ plus the negative dc bias. The sheath thickness for the plasma conditions shown in Fig. 2 (a) is about a few to ten microns. The ion velocity component perpendicular to the surface is significantly stretched due to the sheath acceletation effect. This means that the sample is bombarded with monoenergetic ions. Also, one can consider that ions are striking on the surface at the sample surface at the normal incidence regardiess of ion gyration direction before they enter the sheach region. Major plasma-surface interactions parameters expected in ITER and those one can simulate in PISCES-B are shown in Table 1. Notice that PISCES-B can be an excellent simulator of plasma-surface interactions expected in ITER, particularly at the divertor.

The plasma generator normally runs at a magnetic field of 500 gauss. However, the magnetic field can be varied between 100 and 1000 gauss if necessary. The target region is applied with a magnetic field ranging from 100 to 1000 gauss. The typical magnetic field configuration is shown in Fig. 3. The plasma column diameter can be varied between $3 \mathrm{~cm}$ to $20 \mathrm{~cm}$ by changing the magnetic field. Shown in Fig. 4 (a) are radial profiles of the electron temperature and ion saruration current from the Langmuir probe scanned in front of the sample with a diameter of $5 \mathrm{~cm}$. One sees that the plasma bombardment at the is reasonably uniform. Consistently, as shown in Fig. 4 (b), the radial surface temperature profiles obtained by a CID camera is extremely uniform at elevated temperatures. Here, the CID camera is calibrated by optical pyrometer measurements. This surface temperature uniformity is crucially important in analyzirg the materials erosion and redeposition behavior, particularly if the in situ spectroscopic technique [10] is used. 


\section{MATERIALS EROSION EXPERIMENTS IN PISCES-B}

\section{A. Background}

Graphite has been extensively used as the plasma-facing component material in tokamak fusion facilities. However, the weakness of graphite is that hydrogen plasma bombardment causes chemical sputtering at temperatures frum room temperature to $900^{\circ} \mathrm{C}$ in addition to physical sputtering. Also, radiation enhanced sublimation (RES) of graphite has been observed recently at temperatures above $1000^{\circ} \mathrm{C}$. From a materials erosion viewpoint, therefore, the best temperature range to use graphite under plasma bonbardment is probably in-between 900 and $1000{ }^{\circ} \mathrm{C}$. For reasons too various to mention here, however, none of the fusion reactor design studies has allowed us these optimum temperatures. Unfortunately, ITER does not seem to be an exception in this regard [11].

To compensate the weakness of graphite, considerable effort has been made to develop altemative materials for plasma-facing components. In this work, boronized graphite has been tested as a carbon-alternative material with reduced chemical sputtering and possibly radiation enhanced sublimation. Earlier measurements have shown that small amount of surface impurities can significantly reduce chemical sputtering of graphite while no such observation has been reported for radiation enhanced sublimation. These impurities include metals such as iron [12], ceramics such as $\mathrm{SiC}[13,141$ and also boron [15]. One of the possible mechanisms to explain the impurity-induced suppression of chemical sputtering is that hydrogen recombinative desotption is enhanced at impurity spots on the surface, presumably due to some catalytic effect. Recently, this hypothetical enhanced recombination has been experimentally demonstrated for thermal desorption from metal-contaminated graphite [16].

\section{B. Test materials and experimental details}

The marerials used here include: boronized graphite (Toyo Tanso: G-032) with a boron content of 3\%; (2) isotropic graphite (Toyo Tanso: G-035); and (3) isotropic graphite (POCO: AXF-5Q). These materials are first machined into disks with a diameter of $5 \mathrm{~cm}$ and a thickness of $6 \mathrm{~mm}$. The disk sample was set on an air-cooled sample probe and was placed in a steady-state hydrogen plasma in PISCES-B. The plasma column diameter was set to be about $5 \mathrm{~cm}$, as shown in Fig, 4 (a) and (b). 
The in situ spectroscopic technique [10] was used for erosion yield measurements. Typical hydrogen plasma bombardment conditions are listed in Table 2. Here, the plasma density and the electron temperature were reproduced within an accuracy of $5 \%$ or better for duplicated runs. The sample was heated by the heat due to plasma bombardment. For chemical sputtering experiments, as described in our previous work [17], the $\mathrm{CH}$-band radiation integrated in the wave length from 4270 to $4312 A$ was used as the erosion yield indicator, inclusive of various hydrocarbon molecules emitted from the surface. The $\mathrm{CH}$ band intensity was then calibrated with weight loss measurements conducted separately at about $700^{\circ} \mathrm{C}$. For radiation enhanced sublimation experiments, the $\mathrm{C}$-I radiation intensity at a wave length of $9095 \AA$ was monitored in front of the sample. As will be seen lates, $C-I$ radiation is detected even in the chemical sputtering regime because hydrocarbons are dissociated due to electron impact and liberate carbon atom(s) via molecular break-up processes [18]. The C-I radiation intensity was also calibrated by the weight loss method at $1200^{\circ} \mathrm{C}$.

\section{Chemical sputtering}

Shown in Fig. 5 is the CH-band intensity profiles as a function of distance from the surface in the plasma upstream direction at 550 oC under hydrogen plasma bombardment. Here, the erosion yield is represented by the area below the profile curve. Notice that boronized graphite (Toyo Tanso: G-032) shows significantiy reduced chemical sputtering. relative to iso-graphite (POCO: AXF-5Q). However, no difference was observed for the CH-band profiles for iso-graphites (POCO:AXF-5Q, Toyo Tanso: G-035) and 200 ppm (0.02\%) boronized graphite (POCO: AXZ-5Q) under identical conditions. In earlier experiments, $0.5 \%$ boron-doped graphite showed significantly reduced chemical sputtering due to deuterium ion bombardment at $2 \mathrm{keV}$ [15]. It follows from these independent evidences that there must be a critical concentration of boron to provide observable suppression in chemical sputtering although the critical concentration is yet-to-be explored.

Simultaneously with these spectroscopic measurements, chemical sputtering products escaping from the hydrogen plasma were identified with the differentially pumped RGA. The RGA mass spectra taken at a sample temperature of $550^{\circ} \mathrm{C}$ are shown in Fig. 6. These mass spectra are indicative of $\mathrm{CH}_{4}, \mathrm{C}_{2} \mathrm{H}_{2}$ and $\mathrm{C}_{2} \mathrm{H}_{4}$, and their isotopes and fragments, which is in agreement with earlier observations [19]. Reduction in these peak intensities for 3\% boronized graphite can be easily seen, relative to iso-graphite (POCO: AXF-SQ). From these mass spectra, however, it is not simple to identify $\mathrm{B}_{\mathbf{X}} \mathrm{H}_{\mathrm{y}}$ molecules 
such as $\mathrm{B}_{2} \mathrm{H}_{6}$. The experimental difficulty here is the close resemblance of $\mathrm{B}_{\mathrm{R}} \mathrm{H}_{\mathrm{y}}$ to $\mathrm{C}_{\mathrm{x}} \mathrm{H}_{\mathrm{y}}$ in mass number. Also, in general, $\mathbf{B}_{\mathbf{x}} \mathrm{H}_{\mathbf{y}}$ molecules are extremely unstable at elevated temperatures and are unlikely to be released as they are from the surface, particularly under energetic hydrogen plasma bombardment. In fact, the free energy of formation of $\mathrm{B}_{2} \mathrm{H}_{6}$ is never negative at any temperature and becomes more unstable at higher temperatures [20]. Also, there is no element clearly detected at a position of $\mathrm{M} / \mathrm{c}=11$ which is hypothetically for boron liberated from $\mathrm{B}_{\mathrm{x}} \mathrm{H}_{\mathrm{y}}$ complex due to electron impact in RGA. From these evidences, the surface boron does not seem to be eroded by chemical sputtering.

In TEXTOR, the first wall has been boronized, meaning that plasma-facing surface components are coated with approximately $50 \%$ boron and $50 \%$ carbon [21]. Even in a high boron content case like this, no clear evidence of $\mathrm{B}_{\mathrm{x}} \mathrm{H}_{\mathrm{y}}$ complex formation has been observed during energetic ion bombardment at temperatures above $350^{\circ} \mathrm{C}$ [22]. In contrast, several $\mathrm{B}_{\mathbf{x}} \mathrm{H}_{\mathbf{y}}$ complexes have been observed for the thermal atomic hydrogen reaction with these TEXTOR samples [22]. These findings are indicative of the unstable nature of $\mathrm{B}_{x} \mathrm{H}_{y}$ complexes. In a recent study [23], however, $\mathrm{B}_{2} \mathrm{H}_{6}$ was detected from boron films under hydrogen plasma bombardment at $350 \mathrm{eV}$ but only at relatively low temperatures below $400^{\circ} \mathrm{C}$. This implies that orie might see $\mathrm{B}_{2} \mathrm{H}_{6}$ for pure boron or extremely boron-enriched cases. As to the present data, it is probably difficult to detect $B_{\mathrm{x}} \mathrm{H}_{\mathrm{y}}$ complexes, even they are formed, because the surface concentration of boron is only 3 尔。

Shown in Fig. 7 is the calibrated chemical sputtering yield data as a function of surface temperature. Notice that 3\% boronized graphite (Toyo Tanso: G-032) has shown about 30\% reduced chemical sputtering, relative to iso-graphites. As mentioned earlier, one possible mechanism to explain this reduced chemical sputtering is enhanced recombination at boron-occupied surface spots. However, there have been no reported evidences to support this argument in the case of boron. To rlarify this point, postbombardment thermal desorption experiments are under way.

Also, POCO: AXF-5Q and Toyo Tanso: G-035 exhibit essentially the same chemical sputtering yield. This is not surprising at all. In our previous work [14], various graphites were tested in PISCES-A, and the chemical erosion yields were found to be the same one another. One might refer this to as "the universal erosion behavior" for graphitic materials. This can best be understood as follows: once graphite is bombarded with an energetic hydrogen plasma to a high fluence $\left(10^{21-22}\right.$ ions $\left.\mathrm{cm}^{-2}\right)$, the surface would be significantly damaged into a non-crystalline (amorphous) structure, regardless of the virgin structure, and then exhibits essentially the same chemical erosion yield. Here, the sticking coefficient of the chemical sputtering products, e.g. methane, to graphite at elevated 
temperatures is so small that one can assume no significant retrapping effect due to surface topographies: surface porosity etc.

As to comparison of the present data with the existing data base, one should consider two separate effects. Obviously, the first one is the redeposition effect in PISCES-B shown in Table 2. This requires about a factor of 2.2 adjustment. The second effect needed to be considered here is the ion flux dependence, which is about a factor of 2 against the data taken at ion fluxes of the order of $10^{15}$ ions $\mathrm{cm}^{-2} \mathrm{~s}^{-1}$ [15]. Taking into account these conversion factors, one reaches a hypothetical erosion yield of 0.088 at around $500^{\circ} \mathrm{C}$, which is relatively in good agreement with a reported valuc of 0.1 [19].

\section{Radiation enhanced sublimation}

For radiation enhanced sublimation (RES) experiments, the plasma spectroscopy optics was set up such that C-I radiation is obtained from a sampling volume of about $2 \mathrm{~cm}$ $\times 5 \mathrm{~cm} \times 250 \mu \mathrm{m}$, which is positioned at $2 \mathrm{~cm}$ off from the surface and is the same position as the Langmuir probe. The spectroscopic signal is basically a line-averaged intensity of $C$ I radiation across the plasma column. In this experimental arrangement, as mentioned earlier, it is important to ensure that the plasma properties and surface temperature are uniform across the surface (see Fig. 4).

Shown in Fig. 8 is the C-I radiation intensity as a function of suface temperanue from 200 to $1300^{\circ} \mathrm{C}$. One sees that the $\mathrm{C}-\mathrm{I}$ radiation peaks at around $500^{\circ} \mathrm{C}$, due to chemical spunering. Consistently with the data shown in Fig. 7, boronized graphite exhibits reduced erosion. For temperatures in the chemical sputtering regime, the erosion data is not calibrated by the weight loss method because the CH-band radiation is a better erosion yield indicator than the C-I radiation. The RES erosion yield, however, is calibrated by separate weight loss measurements done at $1200^{\circ} \mathrm{C}$. Notice that boronized graphite has shown significantly rediced erosion in the RES regime as well at temperatures above $900^{\circ} \mathrm{C}$. The temperature range of RES experiments will soon be extended up to 2000 oC using a high temperature sample holder, which is currently under construction. As shown in Fig. 9, POCO: AXF-5Q exhibits a sponge-like porous surface after repeated erosion measurements, while Toy 0 Tanso G-032 and G-035 surfaces remain less porous. Also, in situ AES analysis indicates no significant surface composition change for $3 \%$ boronized graphite: (1) $2.5 \% \mathrm{~B}, 95 \% \mathrm{C}$ and $2 \% \mathrm{O}+\mathrm{N}$ before plasma-exposure; (2) $4 \% \mathrm{~B}$ and $96 \% \mathrm{C}$, after hydrogen plasma to a total fluence of the order of $10^{22}$ ions $\mathrm{cm}^{-2}$. 
As to iso-graphite, the RES erosion yield obtained here is about a factor 2.3 smaller compared with those from earlier measurements at fiuxes of the order of $10^{15}$ ions $\mathrm{cm}^{-2} \mathrm{~s}$ 1, using pyrolytic graphite [24]. However, this discrepancy is not surprising because under the present plasma conditions in PISCES-B, one expects abr , 30 \% reduction in the net erosion due to redeposition [5]. The sponge-like porous graphite surface topography (see Fig. 9) can cause retrapping, which also leads to a reduced net erosion [25]. In fact, the sticking coefficient of evaporated carbon is relatively high: $0.6-0.7$ at around $1200^{\circ} \mathrm{C}$ [26]. These known correction factors can easily make up a factor of 2.3 discrepancy. Apparenty, no additional correction is needed using the flux dependence data such as $Y \propto \Gamma^{0.91-0.93}[24,27]$, which results in a factor of about 2-3 reduction in the RES erosion yield from $10^{15}$ to $10^{18}$ ions $\mathrm{cm}^{-2} \mathrm{~s}^{-1}$. However, it may be too premature to conclude from these arguments that the flux dependence does not hold in the high flux range.

Generally, radiation enhanced sublimation of graphite is interpreted as the process that energetic ion bombardment introduces interstitial carbon atoms, which then rapidly migrate to the surface and spontaneously evaporate ai temperatures lower than one would expect. These interstitivis are often modeled to have a migration (and desorption) energy of around $\mathrm{leV}$ or less [29], which is significantly smaller than the surface binding (i.e., sublimation) energy of $7.4 \mathrm{eV}$. Ont right consider that this drastic change in the effective binding energy is the indieator of "radiation enhancement". Also, the layered hexagonal lattice structure, which is typical of graphite, seems to play an important role in the rapid transport of interstitials.

From the phase diagram of the boron-carbon system [29], on the other hand, one expects segregated carbides, presumably $\mathrm{B}_{4} \mathrm{C}$, even at low boron concentrations around 1\%. Therefore, 3\% boronized graphite tested here falls into this two-phase region. There are still uncertainties in the phase diagram data because of the complex crystalline structures of boron-carbon compounds. In fact, boron carbide has a thombohedral lattice structure: boron icosahedra at the comers of a thombohedral unit cell with two carbon atoms and one boron atom at three lattice positions along the diagonal [30], which is far different from the ordinary graphite structure. Because boron substitutes carton in the solid-solution part, the transport process of interstitials may be affected although unfortunately there is not enough informption about the interstital migration energy etc.

Similar reduction in RES erosion has been observed for $50 \%$ boronized carbon samples from TEXTOR [22]. Since these TEXTOR bomnized samples are in the form of thin film, the lartice structure is frobably not well defined. Nevertheless, these arguments allow us to speculate that modifications of lattice sructure and/or those of chemical bonding 
may suppress radiation enhanced sublimation of graphite. Clearly, more in-depth investigation is needed in this area.

\section{SUMMARY}

The PISCES-B facility has been constructed to perform improved plasma-surface interactions research. The plasma operation space in PISCES-B is: the plasma density ranges from $1 \times 10^{-11}$ to $3 \times 10^{-13} \mathrm{~cm}^{-3}$ and the electron temperature ranges from 3 to 51 eV. By controlling the pumping speed, the neutral pressure during plasma operation can be as high as $1 \times 10^{-3}$ and as low as $3 \times 10^{-5}$ Torr. The plasma bombardment flux can be varied from $1 \times 10^{17}$ to $8 \times 10^{18}$ ions $\mathrm{s}^{-1} \mathrm{~cm}^{-2}$. These conditions are similar to those at the limiter and divertor regions in toroidal fusion devices.

Using the PISCES-B facility, boronized graphites ( $200 \mathrm{ppm}$ and $3 \%$ boron) have been tested and compared with iso-graphites as the reference materials. The erosion yield due to hydrogen plasma bombardment for $3 \%$ boronized graphite has been found to be about 20-30\% smaller than that for iso-graphites both in the chemical sputtering and radiation enhanced sublimation regimes at temperatures from room temperature to $1300^{\circ} \mathrm{C}$. From the nuclear fission technology, the boron isotope ${ }^{10} \mathrm{~B}$ (natural abundance: $20 \%$ ), is well known as an effective "poison" to absorb thermal neutrons, which leads to a nuclear reaction: ${ }^{10} \mathrm{~B}(\mathrm{n}, \alpha)^{7} \mathrm{Li}$. However, the absorption cross section decreases $3-4$ orders of magnitude towards fusion neutron energies around $14 \mathrm{MeV}$ [30]. This allows us to consider that graphite boronized to a low concentration can be one of the possible candidates for plasma-facing components in ITER although bcron isotopes separation may be required to eleminate the thermal neutron absorption effect completely. More systematic evaluation of this boronized materials is under way in collaboration with Sandia National Laboratories and Oak Ridge National Laboratory.

\section{ACKNOWLEDGMENTS}

The authors would like to express sincere gratitude to W.Eatherly, D.M.Goebel, A. A.Haasz, B.LaBombard and H.Ogura for illuminating discussions. This work is supported by the Office of Fusion Energy, U.S. Deparment of Energy under Contract No. DE-AT03-84FR52104. 


\section{REFERENCES}

1. For example, "Sputtering by Particle Bombardment I. and II", R.Behrisch (ed.), Springer-Verlag.

2. J.Roth, J.Ehrenberg, K.Wittmaack, P.Coad and J.B.Roberto, J.Nucl. Mater. 145147, 383 (1987).

3. B.Mills, D.A.Buchenauer, A.E.Pontou and M.Ulrickson, J.Nucl.Mater. 16z-164, 343 (1989).

4. D.M.Goebel, G.A.Campbell and R.W.Conn, J.Nucl.Mater. 111\&112, 457(1984).

5. Y.Hirooka, D.M.Goebel, R.W.Conn, W.K.Leung and G.A.Campbell, 141-143, 193 (1986).

6. See "PISCES Program: Plasma-Surface Interactions Research Program, Summary of Research 1988-1989", PISCES-team, UCLA-PPG\# 1247.

7. D.M.Goebel, Y.Hirooka, T.A.Sketchley, Rev.Sci. Instrum. 56, 1717 (1985).

8. G.L.Jackson, Private communication.

9. B.LaBombard, R.W.Conn, Y.Hirooka, R.Lehmer, W.K.Leing, R.E.Nygren, Y.Ra, G.Tynan and KS.Chung, 162.164, 314 (1989).

10. W.K.Leung, Y.Hirooka, R.W.Conn, D.M.Goebel, B.LaBombard and R.E.Nygren, J.Vac.Sci. \& Technol.-A 7, 21 (1989).

11. For example, ITER-R\&D meeting at General Atomic, San Diego, Jan. 1989. Many of the important design paraneters have not yet been finalized for ITER. One might use the "current" values as the reference.

12. K.Ashida, K.Ichimura, M.Matsuyama and K.Watanabe, J.Nucl.Mater, 148, $217(1987)$.

13. E.Franconi, Y.Hirooka, R.W.Conn, W.K.Lueng, B.LaBombard and R.E.Nygren J.Nucl.Mater. 162-164, 892 (1989).

14. D.M.Goebel, J.Bohdansky, R.W.Conn, Y.Hirooka, B.LaBombard, W.K.Leung, R.E.Nygren, J.Roth, G.R.Tynan, Nucl. Fusion 28, 1041 (1988).

15. J.Roth, J.Nucl.Mater. 145-147, 87(1987).

16. S.Fukuda, T.Hino and T.Yamashina, 162-164, 997(1989).

17. Y.Hirooka, A.Pospieszczyk, R.W.Conn, B.Mills, R.E.Nygren and Y.Ra, J.Vac.Sci.\& Technol.-A 7, 1070 (1989).

18. W.D.Langer and A.B.Ehrthardt, Fusion Technol, 15, 118 (1989),

19. R. Yamada, 145-147, 359 (1987). 
20. JANAF Thermochemical Tables (2nd ed.), Nat.Stand.Ref.Data Ser., Nat.Bur.Stand., (1971).

21. J.Winter, H.G.Esser, L.Köntn, V.Philpps, H.Reimer, J.v.Seggern, J.Schlüter, E.Vietzke, F.Waelbroeck, P.Wienhold, T.Banno, D.Ringer and S. Veprek, J.Nucl.Mater, 162-164, 713 (1989).

22. E.Vietzke, V.Phillips and K.Flaskamp, Proc. US-Japan Workshop P134, Hokkaido, Japan, Feb.6-8, 1989.

23. H.Toyoda, T.Isozumi, H.Sugai and T.Okuda, J.Nucl.Mater. 162-164, 733 (1989).

24. A.A.Haas? and J.W.Davis, J.Nucl.Mater. 151, 77(1987),

25. Y.Hirooka, D.M.Goebel, R.W.Conn, G.A.Campbell, W.K.Leung, K.L.Wilson, R.A.Causey, M.H.Morse, W.Bauer, J.Bohdansky, Nucl.Instr. \& Methods-B 23, 527 (1987).

26. V.Philpps, E.Vietzke and K.Flaskamp, Surf. Sci.178, 806(1986).

27. V.Philipps, E.Vietzke, R.P.Schom, H.Trinkaus, J.Nucl.Mater. 155-157, 319 (1988).

28. J.Roth and W.Möller, Nucl.Instr.Methods-B 7\&8, 788 (1985).

29. C.E.Lowell, J.Am.Ceram.Soc. 50, 142 (1967).

30. R.A.Murgatroyd and B.T.Kelly, Atom. Ene.Rev, 151, 3 (1977). 
Table I Plasma-surface interactions (PSI) in PISCES-A, PISCES-B facilities and TTER.

\begin{tabular}{|c|c|c|c|}
\hline PSI-parameters & PISCES-A & PISCES-E & ITER [11] \\
\hline Plasma species & $\begin{array}{l}\mathrm{H}, \mathrm{D}, \mathrm{He} \\
\mathrm{Ar}, \mathrm{N}\end{array}$ & $\begin{array}{l}\mathrm{H}, \mathrm{D}, \mathrm{He} \\
\mathrm{Ar}, \mathrm{N}\end{array}$ & $\mathrm{D}, \mathrm{T}, \mathrm{He}$ \\
\hline Puise duration (s) & Continuous & Continuous & 200 or longer \\
\hline Plasma density $\left(\mathrm{cm}^{-3}\right)$ & $10^{11}-10^{13}$ & $10^{11} \cdot 10^{13}$ & $\begin{array}{l}=10^{10} \text { for first wall } \\
=10^{14} \text { for diveror }\end{array}$ \\
\hline Electron temperature $(\mathrm{cV})$ & $3-30$ & 3.50 & $=100$ \\
\hline $\begin{array}{l}\text { Ion bombading flux } \\
\text { (ions } s^{-1} \mathrm{~cm}^{-2} \text { ) }\end{array}$ & $10^{17}-10^{18}$ & $10^{17}-10^{19}$ & $\begin{array}{l}=10^{15} \text { for first wall } \\
=10^{19} \text { for divertor }\end{array}$ \\
\hline Target area $\left(\mathrm{cm}^{2}\right)$ & $50-100$ & $50-700$ & \\
\hline $\begin{array}{l}\text { Ionization mean free path } \\
\text { for carbon redeposition }(\mathrm{cm})\end{array}$ & down to 1 & down to 0.5 & down to 0.1 \\
\hline Ion tombarding energy (eV) & $\begin{array}{l}10-500 \\
\text { (de bias) }\end{array}$ & $\begin{array}{l}10-590 \\
\text { (dc bias) }\end{array}$ & $=300-500$ \\
\hline Base pressure (Torr) & $10^{-6}$ & $10^{-8}$ & $=10^{-8}$ \\
\hline Neutral pressure (Torr) & $10^{-4}-10^{5}$ & $10^{-5}-10^{3}$ & $\begin{array}{l}=10^{-5} \text { for first wall } \\
\approx 10^{-3} \text { for divertor }\end{array}$ \\
\hline Plasma \& surface diagnostics & $\begin{array}{l}\text { RGA } \\
\text { Langmuir probe } \\
\text { OMA } \\
\text { Monochromator } \\
\text { TD camera }\end{array}$ & $\begin{array}{l}\text { RGA } \\
\text { Langmuir probe } \\
\text { OMA } \\
\text { Monochromator } \\
\text { CID camera } \\
10 \text { line-of-site por } \\
\text { IR pyrometer } \\
\text { In siru AES+SRM }\end{array}$ & \\
\hline
\end{tabular}


Table 2 Typical conditions in mattrials experiments in PISCES-B.

\begin{tabular}{|c|c|c|}
\hline Parameters & Chemical sputtering experiments & RES erusion experiments \\
\hline Sample & $\begin{array}{l}\text { 3\% boronized graphite (G-052) } \\
.02 \% \text { botonized graphite (AXZ-5Q) } \\
\text { Iso-graphite (G-035) } \\
\text { Iso-graphite ( } \mathrm{AXF}-5 \mathrm{Q})\end{array}$ & $\begin{array}{l}\text { 3\% boronized graphite (G-032) } \\
\text { Iso-graphite (AXF-5Q) }\end{array}$ \\
\hline Radiation monitored & CH-band (4270-4312A) & C-I $(9095 A)$ \\
\hline $\begin{array}{l}\text { Surface temperanure } \\
\qquad\left({ }^{\circ} \mathrm{C}\right)\end{array}$ & $100-900$ (ramp-up) & $200-1300$ (ramp-up) \\
\hline Plasma species & $\mathrm{H}^{+}(85-90 \%), \mathrm{H}_{2}^{+}, \mathrm{H}_{3}^{+}$ & $\mathrm{H}^{+}(85-90 \%), \mathrm{H}_{2}^{+}, \mathrm{H}_{3}^{+}$ \\
\hline $\begin{array}{l}\text { Ion bombarding flux } \\
\text { (ions/s/cn }{ }^{2} \text { ) }\end{array}$ & $2.5 \times 10^{18}$ & $3.5 \times 10^{18}$ \\
\hline $\begin{array}{l}\text { Ion bombarding } \\
\text { energy with dc-bias } \\
\text { (eV) }\end{array}$ & 300 & 400 \\
\hline $\begin{array}{l}\text { Plasma density } \\
\qquad\left(1 / \mathrm{cm}^{3}\right)\end{array}$ & $1 \times 10^{12}$ & $1.3 \times 10^{12}$ \\
\hline $\begin{array}{l}\text { Electron temperature } \\
(\mathrm{eV})\end{array}$ & 25 & 35 \\
\hline $\begin{array}{l}\text { Mean free path for } \\
\text { ionization }(\mathrm{cm})\end{array}$ & $\begin{array}{l}1 \text { for } \mathrm{CH}_{4} \text { at } 600^{\circ} \mathrm{C} \\
\text { (23 for physically spuntered } \mathrm{C} \text { ) }\end{array}$ & 2 for $\mathrm{RES}$-eroded $\mathrm{C}$ at $1000^{\circ} \mathrm{C}$ \\
\hline $\begin{array}{l}\text { Redeposition in } \\
\text { PISCES-B (\%) }\end{array}$ & $\begin{array}{l}\approx 55 \\
(\approx 5 \text { for physically sputtered } C)\end{array}$ & $\Rightarrow 35$ \\
\hline
\end{tabular}




\section{FIGURE CAPTIONS}

Fig.1 : A schematic diagram of the PISCES-B facility at UCLA.

Fig.2 : Plasma generation performance of the PISCES-B facility;

(a) The plasma operation space, compared with that of PISCES-A;

(b) Langmuir probe data taken at a low neutral pressure of $7 \times 10^{-5}$ Torr (see text). A hypothetical effect of the "hot" electron component is jllustrated: a linear line deviating from the thermalized component.

Fig.j : Magnetic field configuration in the PISCES-B facility:B-field contour

(a) Field contour in which magnets and the sample position are siown;

(b) Field configuration along with the major machine axis.

Fig.4 : Typical radial prciles of

(a) Electron temperature and hydrogen plasma ion flux (ion saturation current), both measured with a scanning Langmuir probe;

(b) Surface temperature of the sample measured with CID camera and IR pyrometer under hydrogen plasma bombardment.

Fig.5 : CH-band radiation intensity measured with $\mathrm{OMA}$ as a function of distance from the sample surface. In this case, the surface temperature is $550^{\circ} \mathrm{C}$. Notice that the profile from boronized graphite is clearly lower than iso-graphite.

Fig.6 : Mass spectra obtained from the differentially pumped RGA at a surface temperanure of $550^{\circ} \mathrm{C}$. This data was taken simultaneously with the spectroscopic data shown in Fig.5.

Fig.7 : Chemical sputtering yield data calibrated with weight loss measurements. Notice that boronized graphite exhibits reduced erosion and also iso-graphites st.cw the universal erosion yield (see text).

Fig.8 : Radiation enhanced sublimation data up to $1300^{\circ} \mathrm{C}$. The erosion yield is calibrated with weight loss measurements done at $1200^{\circ} \mathrm{C}$. This calibration is cc nsidered to be valid at temperatures above $-850^{\circ} \mathrm{C}$.

Fig.9 : Hydrogen plasma bombarded sufaces of:

(a) Iso-graphite (POCO: AXF-5O), (b) Iso-graphite (Toyo Tanso: G-035); and

(c) 3\% boronized graphite (Toyo Tanso: G-032), where bright color particles are considered to be the carbide phase $\left(\mathrm{B}_{4} \mathrm{C}\right)$ from separale $\mathrm{X}$-ray analysis (not presented here). 
FIG. 1

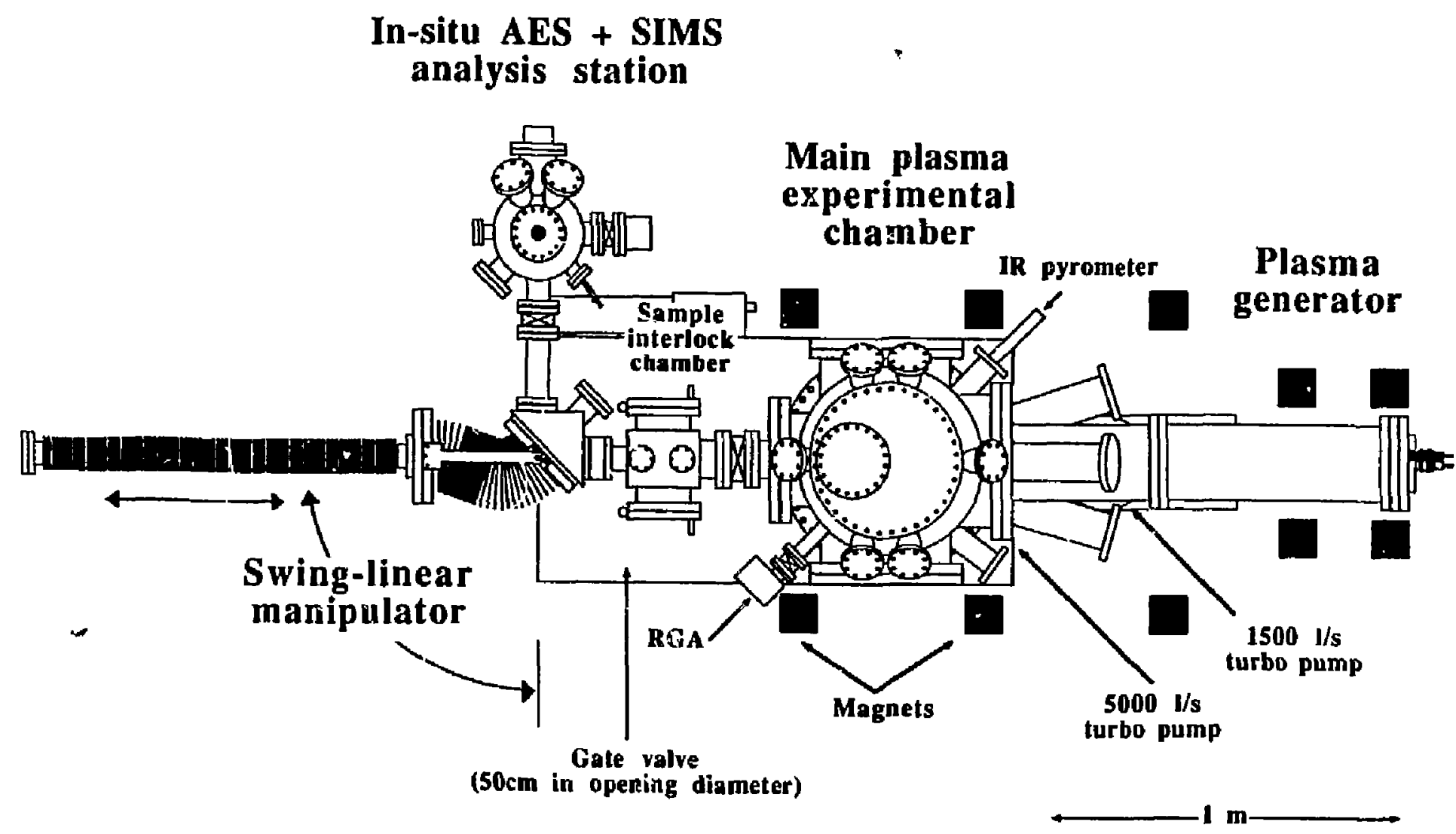

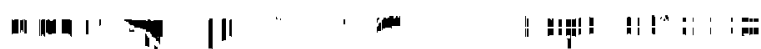


FIG. 2
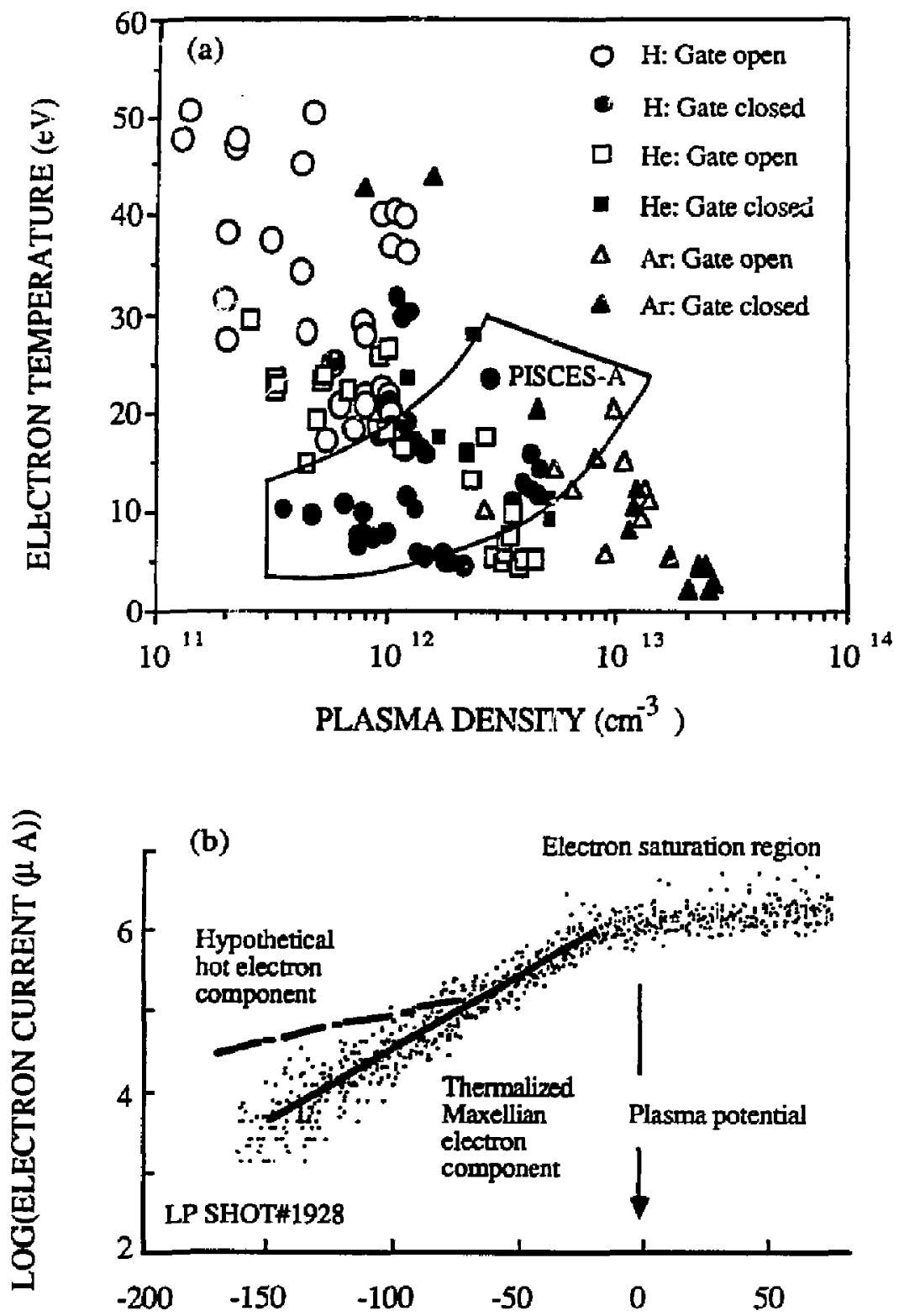

BIAS VOLTAGE ON LANGMUIR PROBE (V) 
FIG. 3

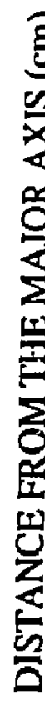

政

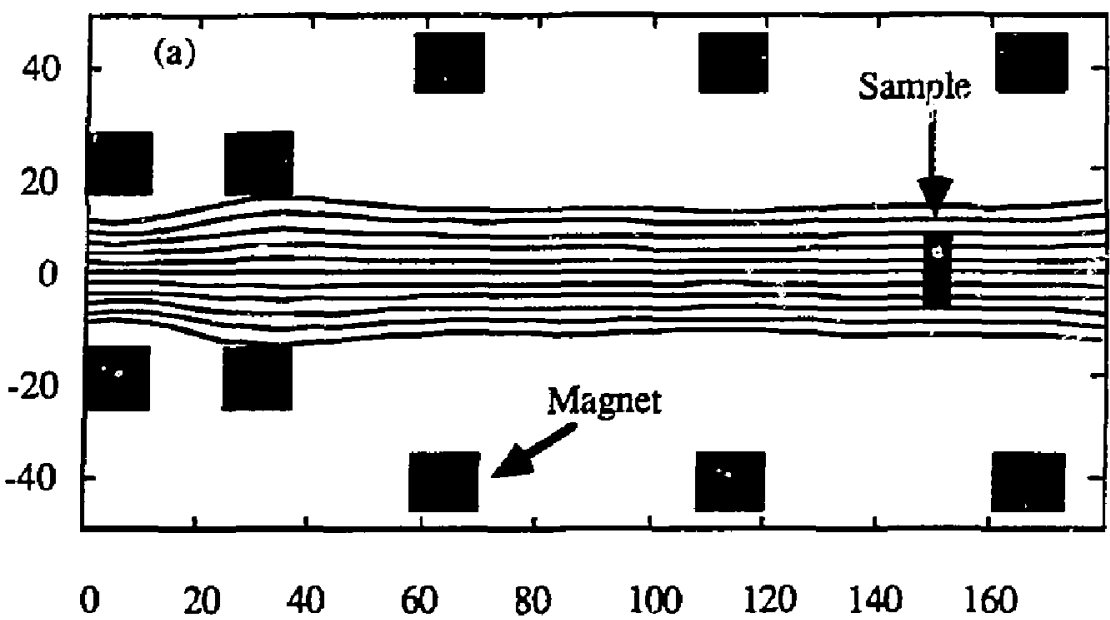

DISTANCE FROM THE PLASMA SOURCE (cm)

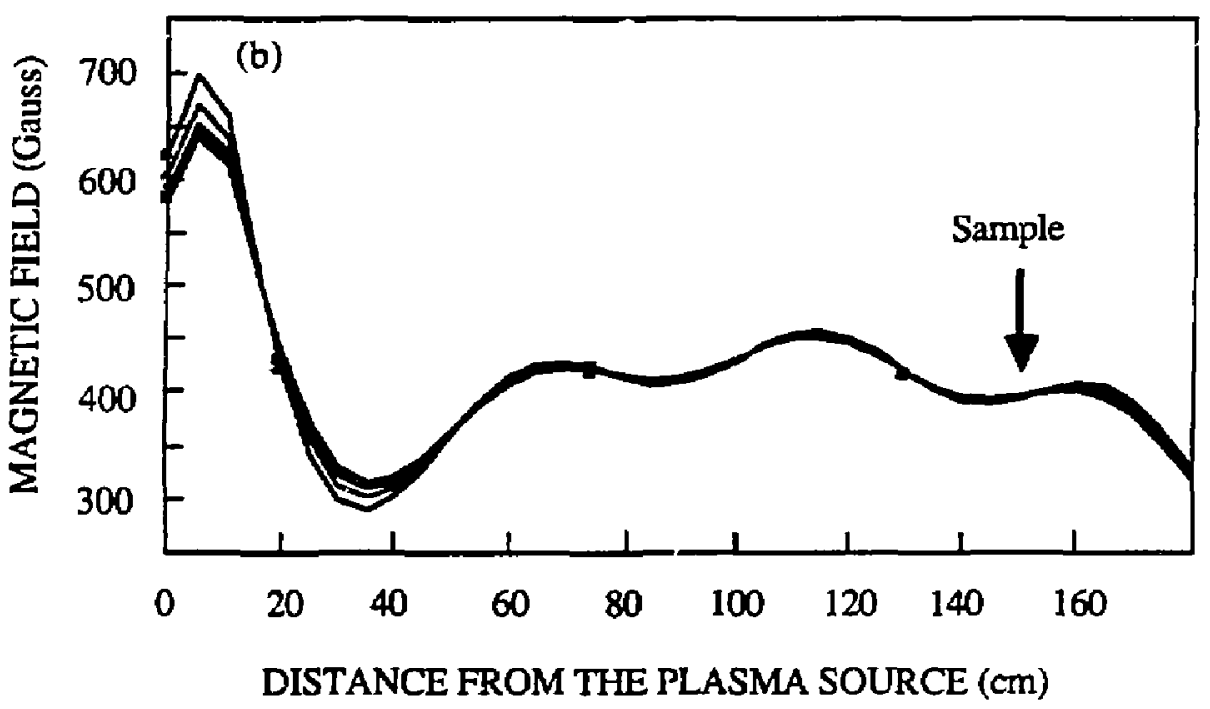


FIG. 4
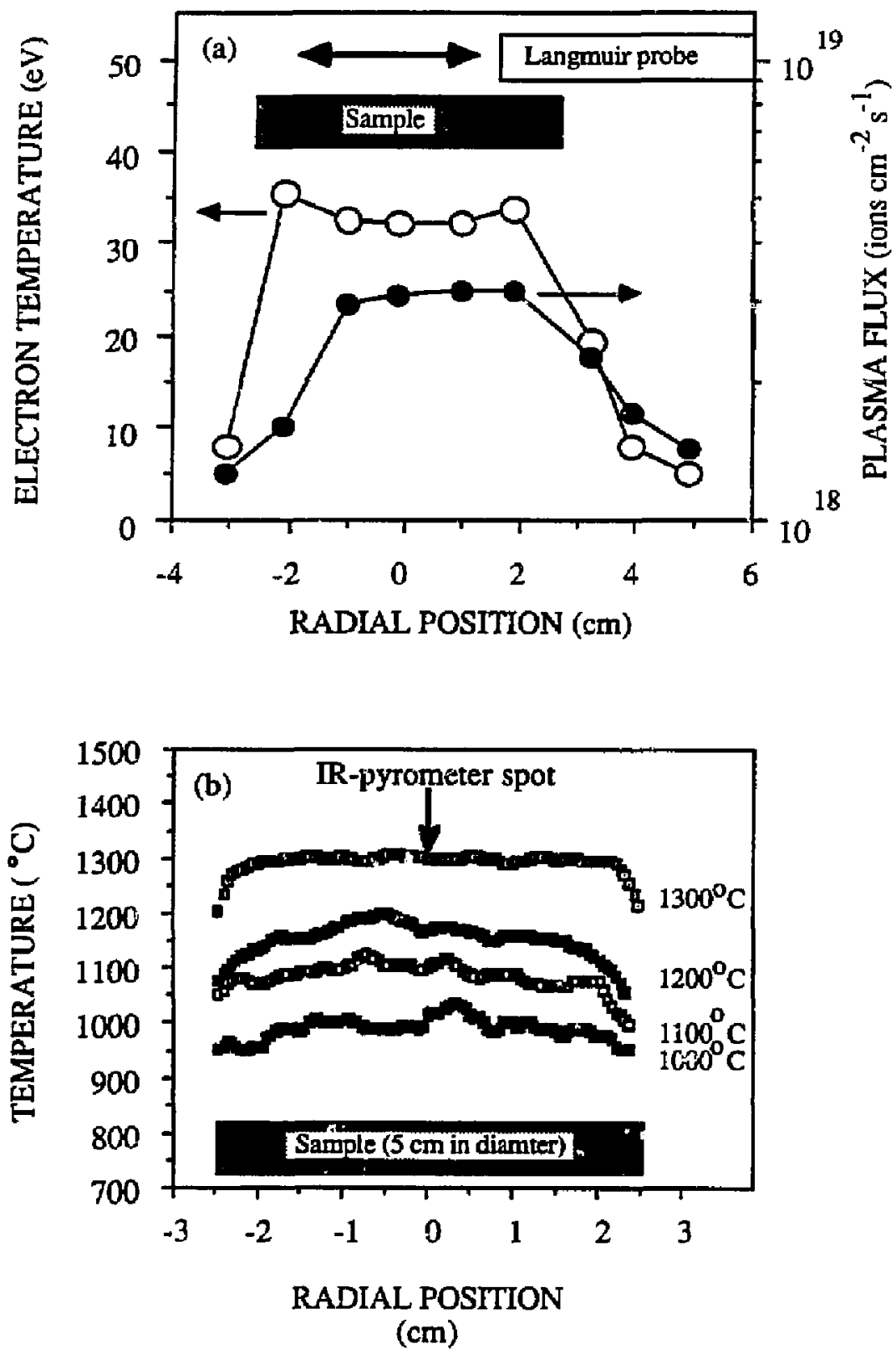
FIG. 5

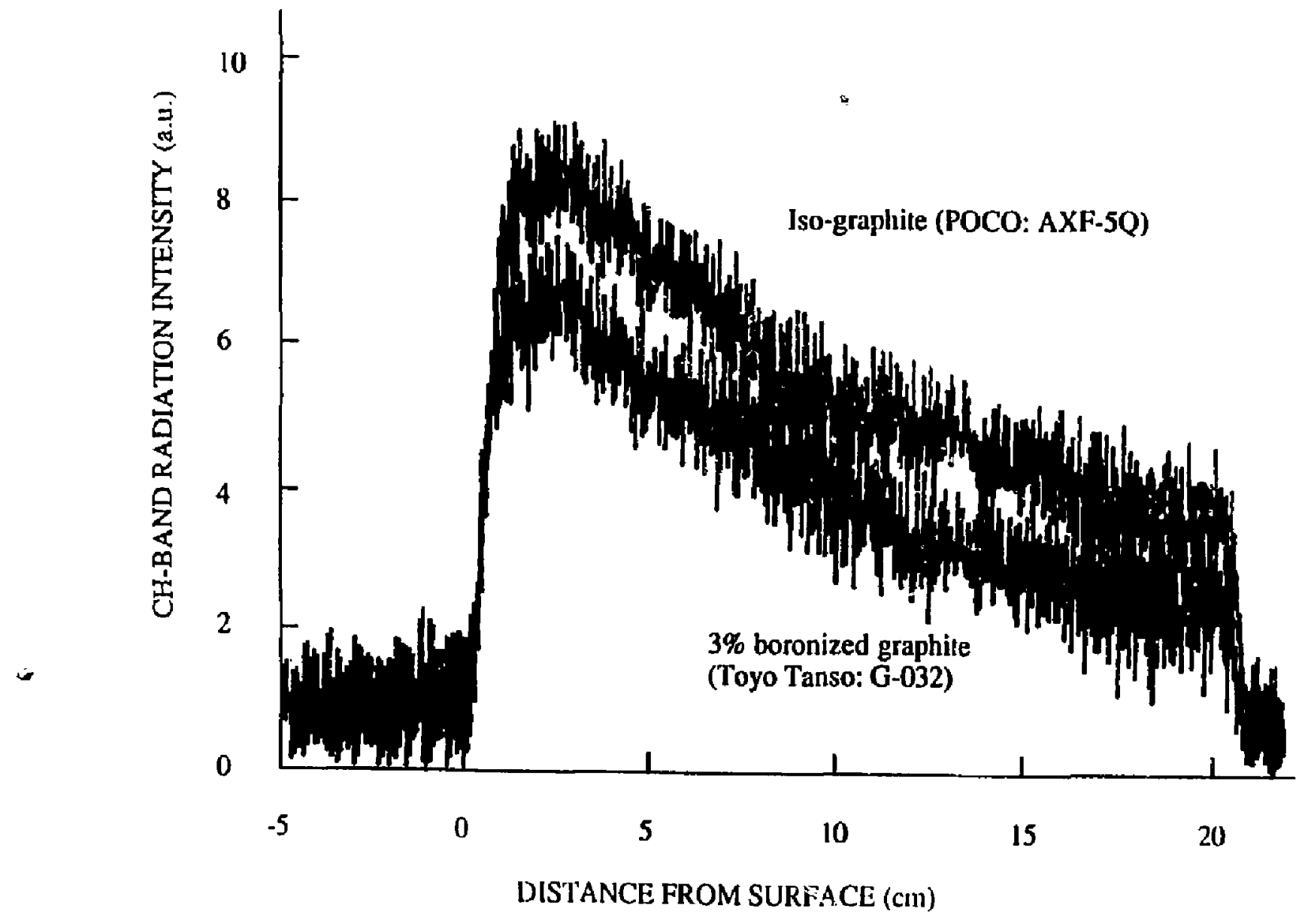


FIG. 6

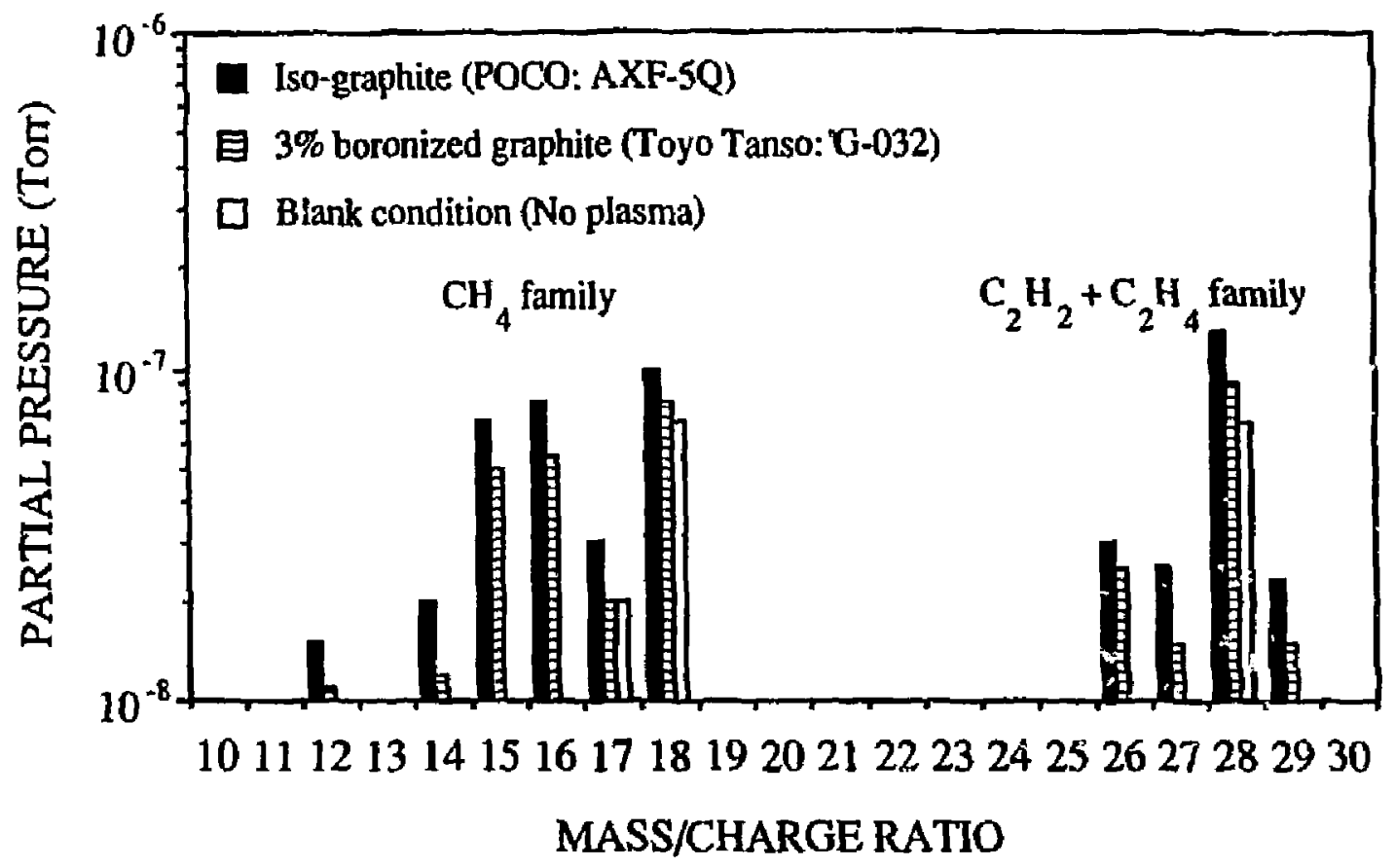


FIG. 7

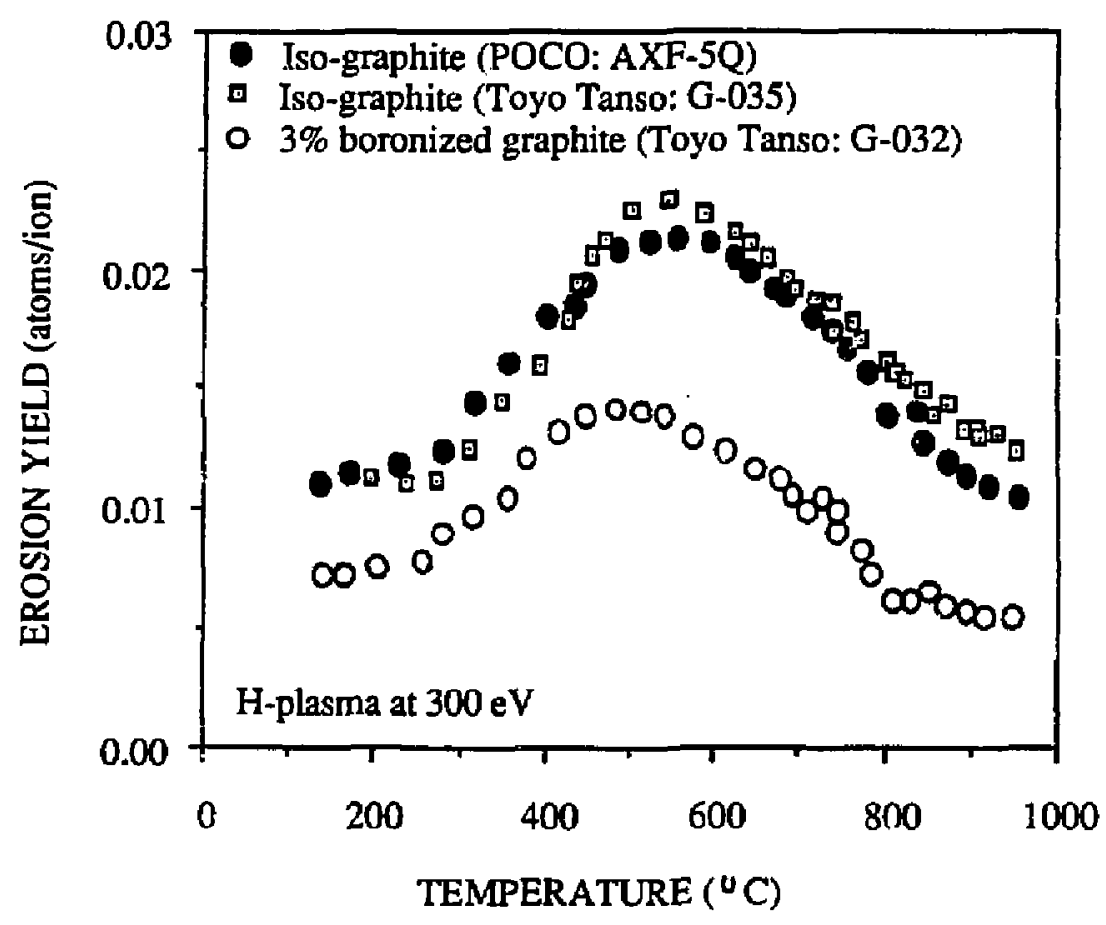


FIG. 8

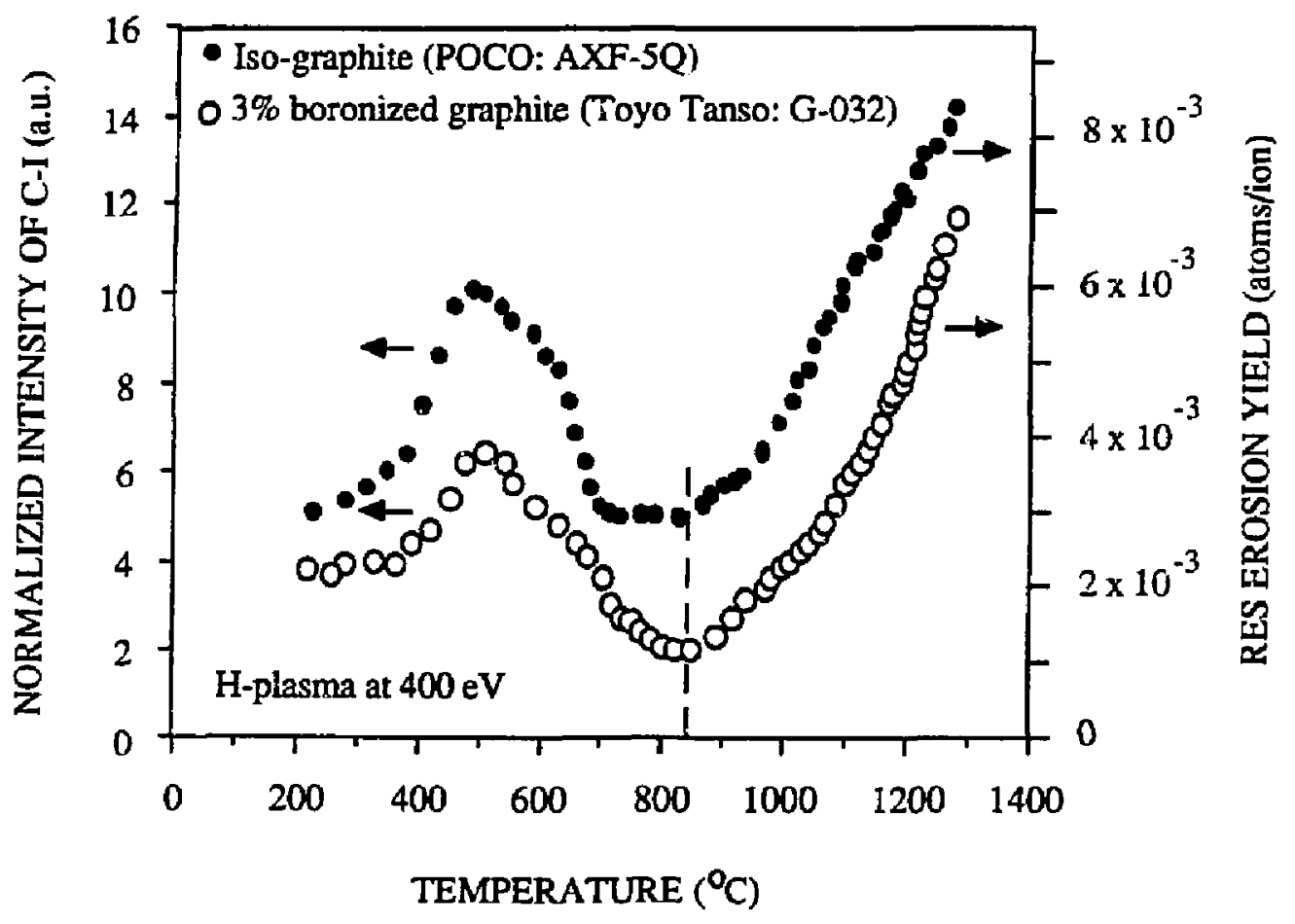


(a)

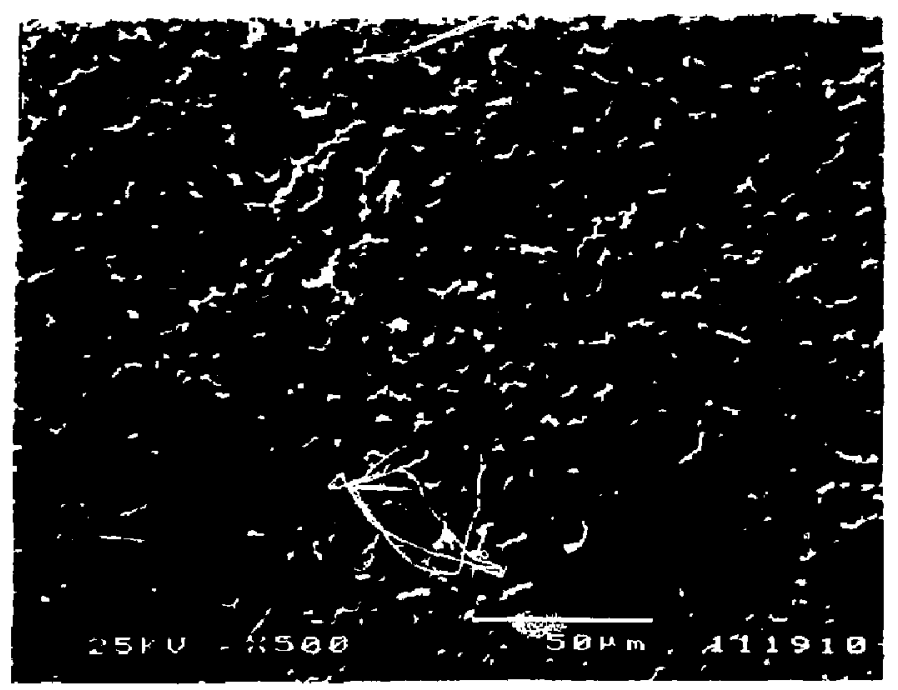

FIG. 9

(b)

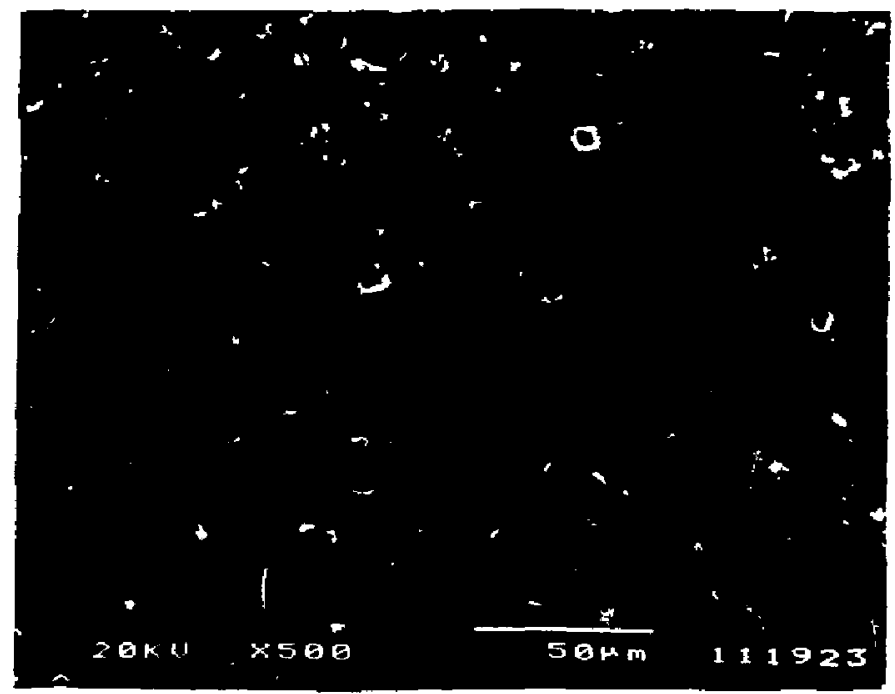

(c)

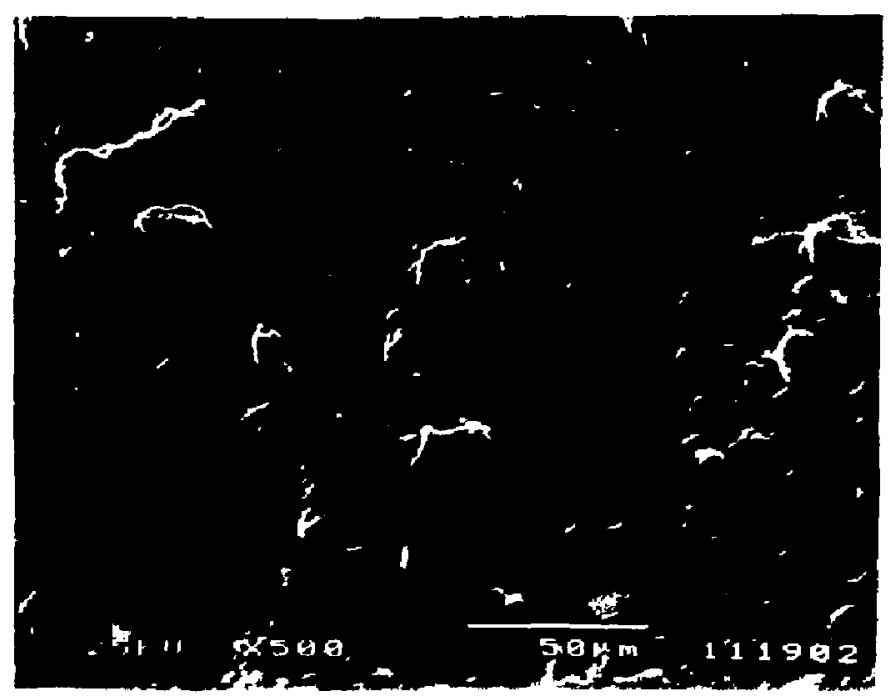

